\title{
Embedding Smart Materials into Products to Motivate the User: Flexers, a Smarter Approach to Finger Splinting
}

\author{
Marco Ajovalasit ${ }^{1}$, Massimo Micocci ${ }^{1}$ and Rob Adam ${ }^{1}$ \\ ${ }^{1}$ Human Centred Design Institute, Brunel University London, Uxbridge UB8 3PH, United \\ Kingdom \\ \{marco.ajovalasit, massimo.micocci\}@brunel.ac.uk, robadam28@gmail.com
}

\begin{abstract}
Embedded intelligence is radically changing the way designers conceptualize and develop technological artifacts. The use of smart materials to design products are uncovering new ways to interact with users so as to engage, entertain and inform them, coding new languages of communication. This study investigates how Smart Materials could support the monitoring of the user's health condition in rehabilitation situations through an embedded input/output system, and how the occurring feedback could be perceived as unobtrusive, easy to understand and motivating. In this study, Flexers, an interactive finger splint is presented which includes adaptive and sensitive materials as a vehicle to achieve an intuitive interaction that promisingly shapes the occurring product experience with renewed engagement of the user. The results suggest that the use of smart materials combined with light based feedback could be used as a motivating tool for engaging the user in the rehabilitation activity.
\end{abstract}

Keywords: Smart Materials - User Experience - Human Centred Design - Interaction Design.

\section{Introduction}

In the last decades material sciences have made technological advancements and discoveries that have radically changed the role consumer products have in everyday life [1], [2], [3]. As a result, technology is progressively more embedded in daily life, producing novel experiences that are enhancing the way the environment and the interaction with products support and entertain us. For example, the Waterradio ${ }^{1}$ by Clemens Winkler combines the technical capacity of a sensor-actuator system on a wooden table with the aesthetic of the natural material to create a unique, new synthesis of surface intelligence. The surface becomes acoustically active when touching water accidentally spilling out of a glass; Christian Iten, Daniel Lüthi \& Emanuel Zgraggen designed "Tangent - a multi-touch surface", interactive multitouch interface that can be used by a number of users at the same time to develop new

\footnotetext{
${ }^{1}$ http://clemenswinkler.com/skin/?cat=7

${ }^{2}$ http://www.designerssaturday.ch/?pageID=203\&lng=en
} 
intuitive forms of interaction; the Hug-ShirtTM by CuteCircuit ${ }^{3}$ is the world's first Touch (Haptic) Telecommunication Device that virtually transmits and receives hugs. In the realm of product design, materials play a fundamental role and they are selected for creating certain experiences and the associated meanings through their characteristics [4], [5]. Based on the view that products are enabler of a users' experience and not their focus, materials should nowadays be considered for their dynamic and responsive qualities (input-output), which could change their properties on demand and adapt to ever-changing user requirements without the need of further mediation/interface, e.g. peripheral devices for input or output.

The field of care \& well-being has been identified by many researchers [7] not only a growth market where the applications of Smart Materials result beneficial to their users, but it is also an area where intuitive-to-use, attractive and non-stigmatizing products can make a real difference. For example, designing for ageing population requires more and more solutions that allow older adults to live independently [8], while people with eating disorders such as obesity, demands specific products to monitor their health and describing correct eating patterns. Example like Future Care Floor [9] shows an instrumental integration of the SMs materials into the home environment. This sensor floor seamless integrates piezoelectric sensors to support old and frail persons living independently at home. The purpose of this application is to detect abnormal behavioural patterns of the inhabitant and activate rescue procedures in case of falls or other emergency events. In this vision, all around matter should be responsive, adaptable and able to convey information without any additional level that could be perceived as intrusive by the user. A particular area of interest where Smart Materials interactions have been proven to be useful is in the field of rehabilitation and sports. For example products like "Radiate Athletics"4 adopt thermochromic pigments to enrich sport garments with the ability to display the body area positively affected by the training performance; Mickael Boulay ${ }^{5}$ designed "Measure less to feel more", a diabetes reader that reduce stress on user while measuring blood sugar level by creating an emotional and engaging experience through dynamic colour effects.

The context of investigation of this paper is grounded on the British Health and Safety Executive (HSE) reports, estimating 201,000 total cases of upper limb disorders of working people, which led to 3.2 million working days being lost in 2013/14 [10]. Musculoskeletal finger injuries is considered an emerging field of investigation where innovative design solutions can counteract the long recovery time, prevent further damages to the tendons and improve the overall experience. A tear to the tendon can take 12 weeks to recover to full strength and up to 6 months to regain a full range of motion [11]. This is a key problem, as patients do not intend to stop using their hands for normal daily activities, therefore potentially causing further damage.

Departing from most of the current literature on Smart Materials, the overarching goal of this paper was to explore how to improve the experience of a rehabilitation device

\footnotetext{
${ }^{3}$ http://cutecircuit.com/collections/the-hug-shirt/

${ }^{4}$ http://www.radiateathletics.com/

${ }^{5}$ http://mickaelboulay.fr/
} 
designing a smart interaction between the user and the product through the application of Smart Materials. This approach in return would help the design community to conceptualize and realize immediate products that is those where the interaction is directly with the product without the intervention of additional interfaces. The potential benefit of this approach is to design technologies that are readily available to a wider inclusive audience, and people can focus on the task which they are involved without concentrating on their interaction with the mediating device. In light of the Human-Centred Design approach [6], this study is based on the assumption claims that Smart Materials can be adopted to simplify the product interactions; the user will therefore benefit from new communicative languages that designers are guided to shape though the dynamic and interactive properties of the Smart Materials. The aim of this paper was to investigate how dynamic materials could support the monitoring of the user's health condition in rehabilitation situations through an embedded input/output system, and how the occurring feedback could be perceived as unobtrusive, easy to understand and motivating for the user. The overarching objective of this work is to design an interactive hand rehabilitation device where sensitive and interactive materials embedded on and within the device could be able to detect changes in the human body and translate the acquired information into intuitive feedback. The ultimate user testing will demonstrate how the novel interaction designed guides the user through the recovery process of musculoskeletal problems. In this paper Flexers, an interactive finger splint, which has been designed by means of adaptive and sensitive materials, is presented as a vehicle to achieve an intuitive interaction that promisingly shapes the occurring product experience with renewed engagement of the user.

\section{Smart Materials and their applications: State of the Art}

"Smart Materials" (SMs) is a relatively new term for materials that have changeable properties and are able to reversibly alter their shape or color in response to physical and/or chemical influences, e.g. light, temperature or the application of an electric field [12]. The Knowledge Transfer Network defines SMs as "materials that display smart behaviours" 6 . A smart behaviour occurs when a material can sense a stimulus from its environment and can react to it in a useful, reliable, reproducible and usually reversible manner. SMs also incorporate features such as sensors and actuators, which are either embedded within a structural material or else bonded to the surface of the material allowing control [13]; the control capabilities permit the behaviour of the material to respond to an external stimulus according to a prescribed functional relationship or control algorithm. This engineered ability brings materials to be applied not only for their physical substance, but also for a combination of input/output signals triggered. A large body of research has been published on the properties of SMs in the last decades as presented in Table 1. However, there is currently lack of a classification of the dynamic properties of the smart materials that can be used support and build the user experiences and novel interactions.

\footnotetext{
${ }^{6}$ https://connect.innovateuk.org/web/smart-materials/smart-design
} 
Table 1. Classification of Smart Materials (SMs)

\begin{tabular}{|c|c|c|c|c|c|c|}
\hline & $\begin{array}{l}\text { Gandhi } \\
\text { et al. } \\
\text { (1992), } \\
\text { [13] }\end{array}$ & $\begin{array}{c}\text { Banks } \\
\text { et al. } \\
\text { (1996), } \\
{[14]}\end{array}$ & $\begin{array}{c}\text { Culshaw } \\
\text { et al. } \\
(1997) \text {, } \\
\text { [15] }\end{array}$ & $\begin{array}{c}\text { Srinivasan } \\
\text { et al. } \\
\text { (2001), } \\
{[16]}\end{array}$ & $\begin{array}{l}\text { Addington } \\
\text { et al. } \\
\text { (2005), } \\
{[17]} \\
\end{array}$ & $\begin{array}{c}\text { Ritter } \\
\text { (2007), } \\
\text { [12] }\end{array}$ \\
\hline $\begin{array}{l}\text { Electro-rheological } \\
\text { fluids }\end{array}$ & $x$ & $x$ & & $x$ & & \\
\hline Piezoelectric materials & $x$ & $x$ & & & & \\
\hline $\begin{array}{l}\text { Shape-Memory materi- } \\
\text { als }\end{array}$ & $x$ & $x$ & & & & \\
\hline Fiber-optic & $x$ & $x$ & & $x$ & & \\
\hline $\begin{array}{l}\text { Electrostrictive Ele- } \\
\text { ments }\end{array}$ & & $x$ & & & & \\
\hline Magnetostrictive Fluids & & $x$ & & & & \\
\hline $\begin{array}{l}\text { Sensing technology: } \\
\text { physical measurement, } \\
\text { chemical and biochemi- } \\
\text { cal sensing in structural } \\
\text { assessment }\end{array}$ & & & $x$ & & & \\
\hline $\begin{array}{l}\text { Actuator Techniques: } \\
\text { Piezolectric and Electro- } \\
\text { strictive materials, } \\
\text { Magnetostrictive mate- } \\
\text { rials, Shape Memory } \\
\text { Alloys, Electrorheologi- } \\
\text { cal Fluids, Electromag- } \\
\text { netic Actuation }\end{array}$ & & & $x$ & & & \\
\hline $\begin{array}{l}\text { Magnetorheological } \\
\text { fluids }\end{array}$ & & & & $x$ & & \\
\hline Vibration absorber & & & & $x$ & & \\
\hline Biomimetic materials & & & & $x$ & & \\
\hline $\begin{array}{l}\text { Property- changing } \\
\text { materials: } \\
\text { Shape-Changing materi- } \\
\text { als, Colour and Optical- } \\
\text { ly changing materials, } \\
\text { Adhesion Changing } \\
\text { materials }\end{array}$ & & & & & $x$ & $x$ \\
\hline $\begin{array}{l}\text { Energy Exchanging } \\
\text { materials: } \\
\text { Light Emitting materi- } \\
\text { als, Electricity - Gener- } \\
\text { ating materials }\end{array}$ & & & & & $x$ & $x$ \\
\hline $\begin{array}{l}\text { Matter - exchanging } \\
\text { materials }\end{array}$ & & & & & & $x$ \\
\hline
\end{tabular}

According to the existing literature, information to the users and type of stimuli to action can be delivered in different ways as follows:

- Augment the expressive and interactive potential of common materials such as in the studies [17], [19], [20], [21];

- $\quad$ Create products that can act and respond without mechanical parts: [22]; 
- Create products that can act and respond autonomously to changing environmental condition [23], [24].

Designers and engineers are starting to deploy the properties of materials to enhance the experience unleashed by products and unlock design opportunities for creative applications. It is therefore reasonable to imagine that products with SMs embedded will not be designed only to improve a functional feature of the product, but mostly to afford and support a more meaningful and immediate interaction with the users.

\section{$3 \quad$ Methods}

The investigation carried out in this work was based on the Human Centred Design approach [6] as a way of using experience to design better products. The method initially focused on existing products and then focused on capturing and understanding users' experiences so as to attune the product to their requirements. The method followed the following steps:

- benchmarking and product analysis on the available products on the market;

- Adopting the principles of gamification so as to define concept requirements for enhancing product engagement.

- Identification of representative concepts directions based on existing products;

- Contextual interviews with physiotherapists, occupational therapists and patients who had suffered from finger injuries to discuss the concepts identified and get novel directions on further developments.

\subsection{Benchmark and existing finger splinting products}

Most finger splints can be split into four categories as shown in Figure 1. The choice of which splint is used is dependent on the injury and the severity of it. Each type of splint has a different level of restriction, ranging from immobilisation of a single joint to the whole hand. Most splints tend to support the injured area statically but there are also dynamic versions available.
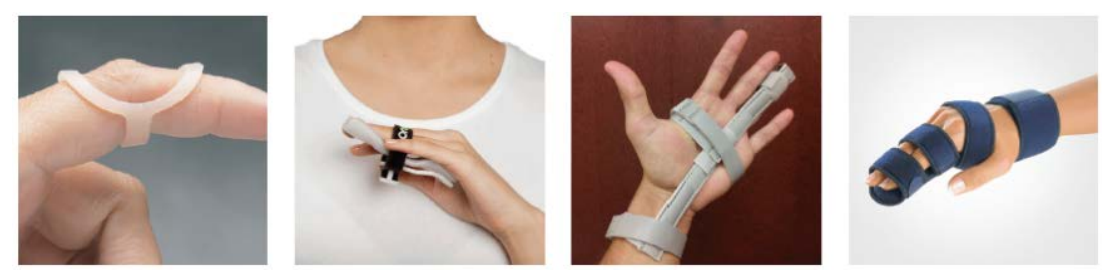

Fig. 1. Existing finger splinting products: a) Joint, b) Finger, c) Full finger, d) Full finger.

\subsection{Gamification by Design}

By analysing the current patient experience, it is possible to identify how the recovery process could be enhanced through the integration of SMs and the gamification of the 
experience to keep patients engaged and adherent. Zichermann and Cunningham [25] define gamification as "The process of game-thinking and game mechanics to engage users and solve problems.”. The gamification of a product is not necessarily about turning it into a game, but using the elements of a game to change the way a human interacts and behaves when using a product to make it more engaging [26]. Three main aspects of gamification [25] were adopted to develop the device: motivating the user, through different levels of difficulty and providing feedback on progress; empowering the user, giving him all the tools and guidance they need to complete his objective; re-engaging the user, by creating a loop of engagement that encourage him to reiterate the interaction.

\subsubsection{Motivating the User}

Psychological motivations could be split into two main categories: intrinsic (internal) and extrinsic (external). It is possible to argue in a medical context that the personal desire to make yourself better is a bigger motivational factor than other people's views. [25]. Because of this it is possible to look at Mark Lepper's design principles for intrinsic motivation and see how they can be used to encourage someone to help themselves. They include: giving the user some control of the activity and when they complete it; continually challenging a user through different levels of difficulty and providing feedback on progress. Providing a level of curiosity that encourages user to learn more about the process. Contextualising the process they are completing so they learn about what they are doing and why [27].

\subsubsection{Empowering the User}

A key part of gaming design is giving the player all the tools and guidance they need to complete their objective. The book Gamification by Design sums up this theory by using the metaphor of a Sherpa guiding a person up a mountain. "Be their sherpa. Give them the status, access, power, and tools to get them where they need to go. Do it right and they'll be yours forever" [25]. This means that you do not need to complete the task for the user, you just need to equip and encourage them to do it for themselves.

\subsubsection{Re-engaging the User}

If playing a game was a linear experience people would lose interest and stop playing, this is why games are built as a loop of engagement. Kumar splits into four key stages: "motivate emotion, call to action, reengage, feedback and reward" [26]. By creating a loop of engagement you encourage a user to interact and reward them for doing so, a form of positive reassurance and reinforcement. 


\subsection{Exploratory Investigation and Concept Refinement}

The preliminary investigation led to a refined concept where both technical and experiential parameters where considered. Particular attention was given on the efficiency of the light signals and the understand ability of the whole interaction. Whilst currently there are a large number of static and dynamic finger splints available on the market, there isn't a portable splint or a device that allows the patient to dynamically monitor their own injury. As a result that means that there is a niche for this kind of product that is only possible due to current advances being made not only SMs, but the smarter implementation of them that make them more accessible and usable to potential users. Three concept directions were initially chosen, as shown in Figure 2, each based around using light as a feedback method to the patient, but allowed for different levels of freedom of movement.

- $\quad$ Fixed - Improving traditional static splinting by using light based feedback as a stress indicator for when the user moves or tenses their fingers too much whilst wearing the splint.

- $\quad$ Flex - Using light based feedback to guide dynamic splinting, to provide the user with information regarding the controlled movement of the splint and highlighting when they are moving too much or too little.

- Free - A 'visual' splint that has no physical restriction, but instead guides the user only through light based feedback about when they should or not should be moving their finger.

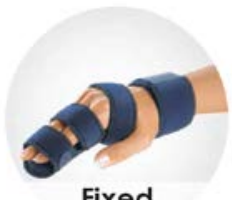

Fixed

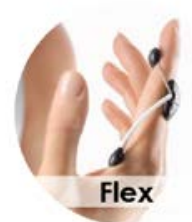

Flex

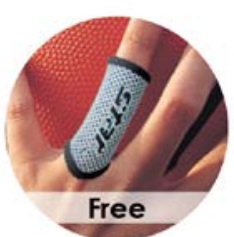

Free

Fig. 2. Three design concept directions based on existing products.

Based on these three concept directions, a focus group with physiotherapists, occupational therapists and people who had suffered from finger injuries was performed with the intent to get direction of further design development. The experts in the focus group agreed on the design of a progressive splint that did not focus on one concept route but focused on adapting to the recovery process, allowing for more movement overtime guided by light, to help a patient recover quicker and better. The splint was divided into a main body and attachments to allow for interchangeable components. In the long term this would allow for a range of different attachments that allow for different ranges of movement that target specific joints. Figure 3 highlights the main areas of strain in the finger. The splint would work by having interchangeable components that would allow for a gradual progression of movement in the device; these components could also change the level of protection provided to the finger. This means that over the course of the recovery, the patient would be 
allowed to move their finger more and reduce the size of the splint. Light based feedback would be used to provide warnings to the patient when they are using their finger too much as to be counterproductive to recovery.

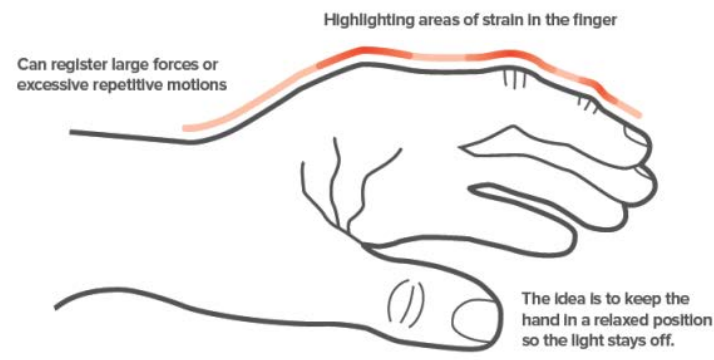

Fig. 3. Highlighting areas of strain in the finger.

In order to create a structured process for design development, it was decided to split the prototyping into the following different key design functions: electronics and user interface; splint main body; splint attachments and strap. This prioritised the most important functions into design synthesis hierarchy that would prove the functionality of the concept. Initial prototyping of the electronics was based around experimenting with different sensors to see how well they would work at recording finger movements. These including using ceramic piezos, PVDF films and flex sensors, the latter proved to be the most successful, as not only did they come in more usable sizes, they were still highly flexible and provided stable and usable data. The adoption of the Arduino board allowed the flex sensor to be attached to the glove and connected to a LED output; the basic interaction achieved was the control of the LED intensity based on the bending of the finger. The application light emitting and electricity generating materials appeared then promising both in terms of quality of output light and integration of the interface to a wearable device. Initially, electroluminescence panels seemed like the most suitable material for this, as they produce a homogenous light but it was found that they were tricky to work with and time consuming. So a switched was made to using flexible LED strips, which saved a lot of time as they are as easy to work with as normal LEDs with the only real drawback being the light is not homogenous. Figure 4 shows the LED strips and flex sensors embedded in initial prototype. After creating a number of this LED strip and flex sensor combination, they were then sewn onto a glove as to improve coding and create an experience prototype that replicated the desired light based warning to the wearer based of their finger movements. 


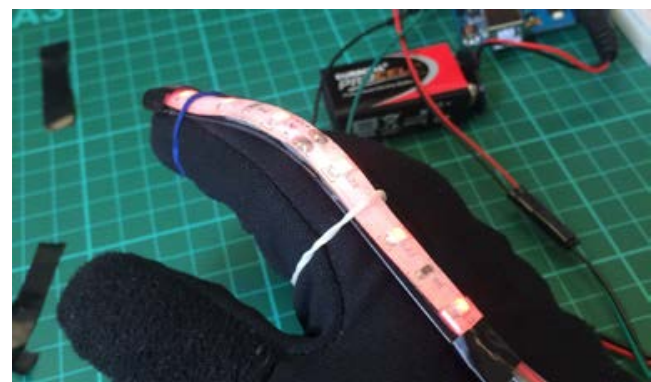

Fig. 4. LED strips and flex sensors embedded in initial prototype.

\subsection{User Testing}

A user testing protocol was employed consisting of a set of interviews and prototype assessment with ten students (mean age 22 years) from Brunel University London with the aim to test the feasibility of using light based feedback as a rehabilitative aid on the dedicated "experience glove", to understand how the users react to the light and finally test the shape of the ultimate plastic splint prototype on a range of different anthropometric size hands to optimise fit and comfort. The experience glove was a supplementary device able to create multiple light feedback aiming to understand people's reaction to the light signals produced and how they will benefit the development of new interactive interfaces. The user test study required participants to wear the "experience glove" for a few minutes, as shown in Figure 5, and answer two questions: What does the light-based feedback is telling you about your finger movements? Which of the colours presented do you think is the best indicator for dangerous finger movements?

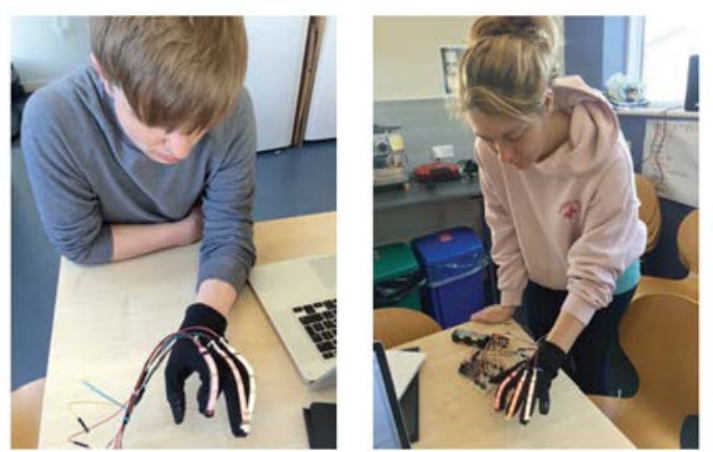

Fig. 5. User testing of the "experience glove".

After the implementation of the intended interaction, the main body of the splint was designed assessing his ergonomics and fit as shown in Figure 6. Through a series of iterative prototypes it was possible to achieve a design that used a single main body and attachments that used living hinges allowing the finger to flex when worn as shown in Figure 6. The moving splint attachment was tested against a to scale 
diagram of the theoretical maximum bend of the prototype. This was to check that it was actually capable of achieving the desired limit of $30^{\circ}$ of movement at each knuckle. From checking the prototype against the diagram, the movement limit of $30^{\circ}$ at each knuckle was near enough spot on. It was only $1^{\circ}$ over at the second joint, though this was more likely due to the prototype quality rather than the design of the hinge at the joint.
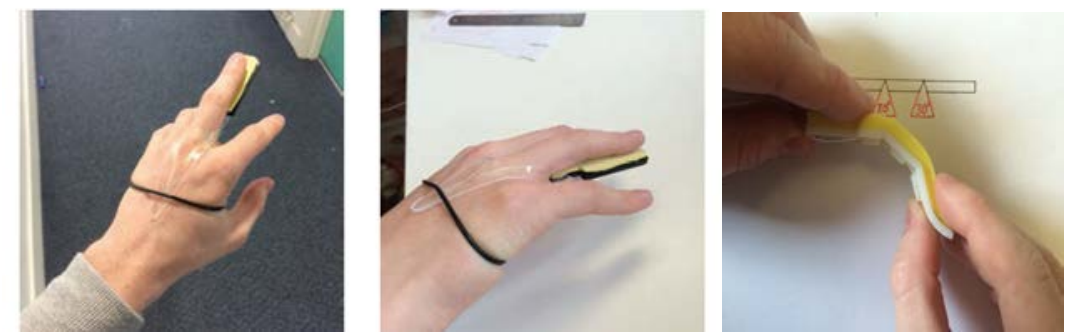

Fig. 6. Experience prototyping of the splint shape and dynamic attachments.

\section{$4 \quad$ Findings}

From the initial user testing with the experience glove, it was clear that most participants presume that when the light gets brighter that the finger movement is not correct, with only one participant saying that it meant nothing. Having explained to them it was a warning, they were then asked which colour they thought was best at this; eight out of ten said the red was the best colour for this. The results found in this work on the assessment of the splint main would suggest that while the size of the splint main body and attachments were not correct for a number of the participants, the shape and fit of the wrap around the finger were comfortable and easy to put on. It was also found that the splint worked well on either hand, for the index, middle and ring finger. The results suggest that users were capable to understand that light based feedback was telling them that their finger movements were dangerous and that it is a warning. This study is the first step towards a structured investigation that aims to consider the technologies as adaptable to human needs and expectations. Through this approach the interactive parameters elicited by the materials work as a connection point between the product features and the user expectations. The possibility we have to shape and engineered, smart materials based on our requirements is a great opportunity designers should consider. Nonetheless, there is a strong need to systematically organize the potentialities of SMs in a method that designers can easily adopt. Working on materials has the primary benefit that every single object could be embedded with different dynamic properties. Matter is everywhere and that matter could be designed to be responsive, adaptable and able to convey different qualities of information. Responsive devices are, then, less invasive and have more possibilities to be socially accepted. The human body owns an undefined set of possibilities that Smart Materials can disclose and exploit for different purposes. The knowledge gained from creating the experience glove allowed for the creation of a works like prototype which took the prototyped dynamic splint design and integrated the electronics into the body as shown in Figure 7. This helped integrating the light based feedback into the context 
of the design application by allowing the user to put on a finger splint that does allow the user to move his finger, but provides warnings when he does it too much.

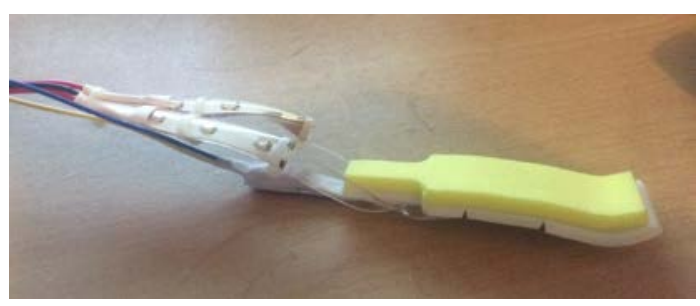

Fig. 7. Work like prototype with integrated electronics.

\section{Conclusions}

This study provides a practical demonstration of the opportunities offered by SMs with the aim to investigate how new technology could be embedded to improve the performance of everyday products and how we experience them in a systematic way. Within this work, the use and application of SMs as mean of immediate interaction, have allowed to enhance with sensing and reacting capabilities a finger rehabilitation tool. The key to the success of SMs in this application is the perception of the interface as completely integrated in the device, as it was an "invisible" guide supporting the user. The study presented is a first step to empirically frame the value that SMs could have to produce unmediated experiences and overcome the barrier of traditional product interfaces in a finger rehabilitation tool. Further testing and development into how light based feedback could be used as a rehabilitative tool should be fully exploited. There is a lot of potential ground for experimenting with the application of the warning system to different supports and also different areas of the body. Also further development is needed to create a secondary layer of feedback to the user, by exploring interconnectivity with a smart phone to provide data about the recovery processes allowing for a user to monitor their actual progress.

Acknowledgments. This research study has been supported by the EU-funded FP7 collaborative research project Light.Touch.Matters (LTM), under agreement n³10311.

\section{References}

1. Jung H, Stolterman E. Form and materiality in interaction design: A new approach to HCI. Proceedings of the 2011 annual conference extended abstracts on human factors in computing systems. 2011:399-408.

2. Kuniavsky M. Smart things: Ubiquitous computing user experience design: Ubiquitous computing user experience design. Elsevier; 2010.

3. Peters S. Material revolution: Sustainable and multi-purpose materials for design and architecture. Walter de Gruyter; 2011. 
4. Karana E, Hekkert P, Kandachar P. A tool for meaning driven materials selection. Mater Des. 2010;31(6):2932-2941.

5. Karana E, Pedgley O, Rognoli V. Materials experience: Fundamentals of materials and design. Butterworth-Heinemann; 2013.

6. FDIs I. 9241-210: 2009. Ergonomics of human system interaction-part 210: Human-centred design for interactive systems (formerly known as 13407). International Organization for Standardization (ISO).Switzerland. 2009.

7. Wim Poelman and Eric Tempelman. Organic interfaces, Tools and methods of competitive engineering: Digital proceedings of the tenth international symposium on tools and methods of competitive engineering. TMCE 2014, Budapest, Hungary, 19-23 May 2014, Delft University of Technology; 2014.

8. Gabriella Spinelli, Massimo Micocci and Marco Ajovalasit. 2015. Behavioural strategies of older adults in the adoption of new technology-based products: the effects of ageing and the promising application of smart materials for the design of future products. Design for Health, Gower \& Ashgate Publishing (in press)

9. Klack L, Möllering C, Ziefle M, Schmitz-Rode T. Future care floor: A sensitive floor for movement monitoring and fall detection in home environments. In: Wireless mobile communication and healthcare. Springer; 2011:211-218

10. HSE. Musculoskeletal Disorders in Great Britain 2014. 2014. Retrieved November 07, 2014 from http://www.hse.gov.uk/Statistics/causdis/musculoskeletal/msd.pdf

11. NHS. Tendon injury recovery. 2015. Retrieved April 15, 2014 from http://www.nhs.uk/Conditions/tendonhand/Pages/Recovery.aspx

12. Axel Ritter, A., 2007. Smart materials: in architecture, interior architecture and design. Springer

13. Gandhi MV, Thompson BS. Smart materials and structures. Springer; 1992.

14. Banks HT, Smith RC, Wang Y. Smart material structures: Modeling, estimation and control. Wiley New York; 1996.

15. Culshaw B, de Vries M. Smart structures and materials. Optical Engineering. 1997;36 (2):616-616.

16. Srinivasan AV, McFarland DM. Smart structures: Analysis and design. Cambridge university press; 2001.

17. Addington M, Schodek D. Smart materials and technologies. Architecture and Urbanism 5 (3). 2005:8-13.

18. Qi J, Buechley L. Animating paper using shape memory alloys. . 2012:749-752.

19. Saul G, Xu C, Gross MD. Interactive paper devices: End-user design \& fabrication. . 2010:205-212.

20. Kaihou T, Wakita A. Electronic origami with the color-changing function. . 2013:7-12.

21. Berglin L. Spookies: Combining smart materials and information technology in an interactive toy. 2005:17-23.

22. Coelho M, Ishii H, Maes P. Surflex: A programmable surface for the design of tangible interfaces. . 2008:3429-3434.

23. Kuswandi B, Wicaksono Y, Abdullah A, Heng LY, Ahmad M. Smart packaging: Sensors for monitoring of food quality and safety. Sensing and Instrumentation for Food Quality and Safety. 2011;5(3-4):137-146.

24. Minuto A, Nijholt A. Growing grass: A smart material interactive display, design and construction history. 2012:7.

25. Gabe Zichermann and Christopher Cunningham. 2011. Gamification by design. Sebastopol, Calif.: O'Reilly Media. Pp.xiv.

26. Pereira, P., Duarte, E., Rebelo, F. and Noriega, P. (2014). Design, User Experience, and Usability. User Experience Design for Diverse Interaction Platforms and Environments. Cham: Springer, pp.742-753.

27. Kapp, K. (2012). The gamification of learning and instruction. San Francisco, CA: Pfeiffer. 